\title{
ESTUDO DO METABOLISMO ENERGÉTICO MUSCULAR EM ATLETAS POR ${ }^{31}$ P-ERM
}

\author{
Maria Gisele dos Santos*, Jose Manuel González de Suso, Angel Moreno, \\ Miquel Cabanas, Carles Arus \\ Trabalho realizado na Univerdade Federal do Paraná e Universidade \\ Autónoma de Barcelona, Barcelona, Espanha.
}

RESUMO - Objetivo. Caracterizar as reservas energéticas de metabólitos fosforilados no músculo esquelético de atletas mediante ${ }^{31}$ P-ERM.

Métodos. Amostra deste estudo foi formada por 14 atletas de alto nível do Centro de Alto Rendimento Esportivo (CAR, Sant Cugat del Vallés, Espanha). $O$ padrão de metabólitos fosforilados foi medido no músculo vasto medial por ${ }^{31}$ P-ERM. A suplementação oral foi realizada durante 14 dias, na forma de $20 \mathrm{~g}$ de monohidrato de creatina. Os atletas foram determinados conforme as suas características físicas (peso, altura, índice de massa corporal (IMC), consumo máximo de oxigênio $\left(\mathrm{VO}_{2}\right.$ Max.) em dois grupos: placebo (maltodextrina) e suplementação com creatina. 0 protocolo de exercício foi realizado no interior do túnel de ressonância $(160 \times 52 \mathrm{~cm})$, a 60 ciclos por minuto para ambas as pernas.
Resultados. Os resultados demonstraram um aumento significativo da fosfocreatina (PCr) durante o exercício, após o período de suplementação, denotando uma redução do seu consumo no grupo que recebeu suplementação com creatina; não houve diminuição significativa do $\mathrm{pH}$ intracelular e fosfato inorgânico após a suplementação.

Conclusão. 0 protocolo de exercício realizado pelos fundistas no Centro de Diagnóstico de Pedralbes permitiu detectar mediante ${ }^{31} P$-ERM, no grupo que foi suplementado com creatina, uma diminuição do consumo de $\mathrm{PCr}$ durante os períodos de exercício.

UnITERMOS: Suplementação de creatina. Espectroscopia de ressonância magnética.

\section{INTRODUÇÃO}

A creatina é um composto que em humanos é sintetizada de forma endógena no fígado, no pâncreas e nos rins, a partir de dois aminoácidos precursores: arginina e glicina. A síntese começa com a transferência de um grupo amino da arginina à glicina, em uma reação de transaminação, para formar guanidinoacetato e ornitina. A enzima que catalisa esta reação reversível é uma transaminase!. A creatina é formada pela cessão de um grupo metil da S-adenosilmetionina ao guanidinoacetato, mediante uma metiltransferasa. Uma vez sendo a creatina sintetizada endogenamente ou ingerida na dieta, é captada pelo tecido muscular, sendo fosforilada mediante a reação catalisada pela creatina quinase, a fosfocreatina. $O$ músculo não tem a capacidade de sintetizar a creatina, e portanto a creatina transportada pelo sangue deve ser captada contra um gradiente de concentração por parte de um transportador de creatina/sódio.

* Correspondência

Rua Brigadeiro Franco, 1909 - apto. 903 CEP: 80230-100 - Curitiba - PR E-mail: mariagisele@yahoo.com
No entanto, a fosfocreatina pode transformar-se de maneira espontânea em um produto cíclico, a creatinina, que acaba sendo excretada na urina? ${ }^{2}$.

A creatina total em humanos é definida como a soma da creatina em forma livre e fosforilada. As maiores concentrações de creatina total no corpo são encontradas no músculo esquelético, com aproximadamente 95\% do conteúdo de creatina total. Mediante biópsia do músculo, pôde-se determinar que a quantidade média de creatina total é de 124,4 mmol/kg de peso seco de músculo, sendo deste, $49,0 \mathrm{mmol} / \mathrm{kg}$ creatina livre (39\%) e 75,4 mmol/kg fosfocreatina (61\%). Os $5 \%$ restantes de conteúdo corporal de creatina estão localizados principalmente no cérebro e coração. Esta distribuição de creatina no corpo indica que esta é transportada pela corrente sanguínea, desde os lugares de síntese até os lugares de utilização!

Entretanto, a suplementação com creatina, converteu-se, durante estes últimos anos, em uma prática habitual entre desportistas de competição, que praticam diferentes especialidades desportistas. O mecanismo pelo qual a suplementação com creatina poderia ter efeitos ergogênicos potenciais consistiria em um aumento do conteúdo muscular de creatina e fosfocreatina, o qual permitiria um aumento na velocidade de ressíntese de ATP, uma diminuição da fadiga muscular e uma melhor recuperação durante exercícios repetidos de alta intensidade. Tem-se estudado de forma bastante completa os efeitos da suplementação com creatina em pessoas sedentárias ou moderadamente treinadas, em condições de laboratório. No entanto, sabe-se muito pouco sobre sua possível influência em desportistas bem treinados participando em competições. Os atletas estudados que foram suplementados com creatina apresentaram melhores resultados, principalmente nos esportes que requerem atividades de alta intensidade. O mecanismo pelo qual a suplementação de creatina aumenta o rendimento pode estar diretamente relacionado com o aumento nos níveis de $\mathrm{PCr}$ no período de repouso e uma maior ressíntese de $\mathrm{PCr}$ durante a recuperação3. Portanto a suplementação com creatina pode trazer benefícios para atletas de alto rendimento, principalmente nos esportes de alta intensidade, como na diminuição da fadiga muscular durante os treinamentos, possibilitando a realização das sessões de treinamento com intensidades mais elevadas. Esse estudo 
teve como objetivo caracterizar as reservas energéticas de metabólitos fosforilados no músculo esquelético de atletas mediante ${ }^{31}$ P-ERM, para detectar o efeito da suplementação com creatina no metabolismo energético muscular.

\section{MÉTOdOS}

\section{Sujeitos}

Todos os atletas foram previamente informados do tipo de estudo do qual participararam e formalizaram, por escrito, seu consentimento ao responsável. O protocolo e as fichas de consentimento foram previamente aprovados pela Comissão de Ética em Experimentação Animal e Humana da Universidade Autônoma de Barcelona.

Amostra deste estudo foi formada por 14 atletas de alto nível do Centro de Alto Rendimento Esportivo (CAR, Sant Cugat del Vallés). Os atletas competiam em eventos de nível regional, nacional e internacional, e um deles participou de campeonatos mundiais. Durante o período do protocolo de análises, os atletas treinavam aproximadamente entre $1-2$ horas por dia, e completavam uma distância total de corrida de 70 - $150 \mathrm{~km}$ por semana.

Os atletas foram ao Centro Diagnóstico de Pedralbes (CDP) (2 -3 horas depois da última refeiçãa) para obter os dados por ressonância magnética (MR). O padrão de metabólitos fosforilados foi medido no músculo vasto medial por ${ }^{31}$ P-ERM.

\section{Suplementação da dieta}

A suplementação oral foi realizada durante 14 dias, na forma de $20 \mathrm{~g}$ de monohidrato de creatina. Os atletas foram divididos, conforme as suas características físicas (peso, altura, índice de masa corporal (IMC), $\mathrm{VO}_{2}$ max.), em dois grupos: placebo (maltodextrina) (grupo 2) e suplementação com creatina (grupo 1). Nos dois grupos, a dose diária foi dividida em quatro porções iguais, repartidas ao longo do dia, para serem ingeridas depois de serem diluídas em um copo de água (aproximadamente $250 \mathrm{ml}$ ).

\section{Descrição do ergômetro utilizado para realizar o protocolo de exercício no interior do aparelho de ressonância}

Tendo em conta as limitações de espaço $(160 \times 52 \mathrm{~cm})$ e o alto campo magnético ( I,5 Teslas) que encontramos no interior do túnel de ressonância, foi utilizado um ergômetro
Figura I - Vista do ergômetro utilizado no experimento

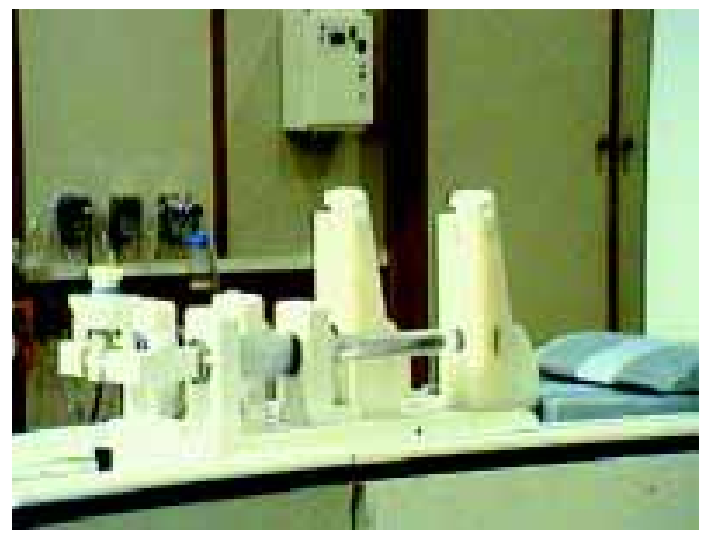

Figura 2 - Vista do ergômetro entrando no túnel de ressonãncia

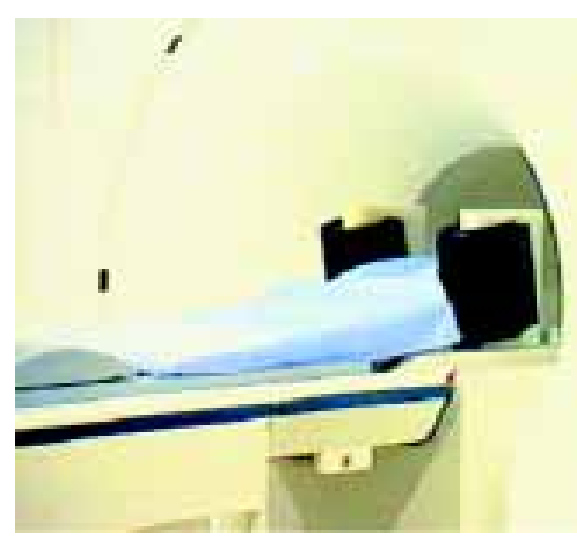

apropriado para realizar exercício nas ditas condições. $\bigcirc$ ergômetro permite a realização de um exercício de pedaladas sobre um plano horizontal, quando o desportista está em posição supina. $\bigcirc$ ergômetro é constituído por um conjunto de dois cilindros, que se encontram emendados em seus extremos mediante um circuito hidráulico. Este circuito apresenta uma válvula, que regula a entrada da água de um cilindro ao outro. Cada cilindro tem um pistão de com aros de borracha de neoprene para evitar fugas de água. As bielas dos pistões terminam em dois pedais com guia, que podem se deslocar cerca de $13 \mathrm{~cm}$. No interior do pedal direito, foi colocado um transdutor de força piezoelétrico (KISTLER Instrumente $A G$, Winterthur, Switzerland) que permite recolher os dados mecânicos. É a única parte metálica do sistema, longe da bobina de superfície e da zona de máxima homogeneidade do campo magnético e não interfere na detecção do espectro de RM. Em seu extremo superior, colocou-se dois tacos de plástico, forrados de borracha, que servem de apoio para os ombros, com os quais se evita que o desportista se deslize para acima ${ }^{4}$ (Figuras | e 2).

\section{Protocolo de exercício realizado no CDP}

O ergômetro utilizado no Centro Diagnóstico de Pedralbes (CDP), foi descrito ${ }^{4}$. O protocolo de exercício foi realizado no interior do túnel de ressonância $(160 \times 52 \mathrm{~cm})$. 0 exercício foi realizado a 60 ciclos por minuto para ambas as pernas, durante três níveis de dois minutos de exercício, a uma intensidade de aproximadamente $93 \%$ da potência máxima de cada atleta, separados por um minuto de repouso. 


\section{Experimentos de ${ }^{31} \mathrm{P}$-ERM}

Os espectros de ${ }^{31} \mathrm{P}$ de repouso foram obtidos utilizando uma bobina emissora/ receptora superficial elíptica $(6,5 \mathrm{~cm} \times 14,5$ $\mathrm{cm})$ desenvolvida previamente pelo grupo ${ }^{4}$, pré-sintonizada com a freqüência de ressonância do fósforo. A bobina foi situada e fixada sobre a perna, com uma faixa elástica em cima do músculo vasto medial. Foi utilizada uma seqüência de pulsos de Spin-Echo com um campo de visão de $240 \mathrm{~mm}$ de diâmetro, um tempo de repetição (TR) de 600 ms, um tempo de eco (TE) de 20 ms e uma espessura de secção de 20 mm. Foi adquirida uma matriz de 256 × 128 com um tempo total de aquisição das imagens de $95 \mathrm{~s}$. Previamente à aquisiçãa dos espectros de fósforo, foi optimizada a homogeneidade do campo magnético sobre o músculo, observando o sinal da água no espectro de protón do músculo, mediante o uso da bobina de corpo como emissora e a bobina de superfície como receptora. $O$ espectro de ${ }^{31} \mathrm{P}$ foi adquirido utilizando um pulso de $180^{\circ}$ no centro da bobina. Foram selecionados um total de 1024 pontos sobre uma amplitude espectral de $2500 \mathrm{~Hz}$. Foram acumuladas quatro FIDs (Free Induction Decay) para permitir a magnetização transversal para chegar a um estado de equilíbrio seguido de outros 128, que foram utilizados para cada espectro com um tempo de reciclagem de $2 \mathrm{~s}$. Isto dava um tempo experimental total de 4,5 minutos por espectro.

No caso do protocolo dinâmico, foram utilizados os mesmos parâmetros de aquisição. Entretanto, para permitir uma somatória de FID's, estes FID's se adquiriram de uma maneira contínua durante todo o período do protocolo de exercício com uma periodicidade de, aproximadamente, dois segundos. O disparo da aquisição de cada FID durante os períodos de exercício foi realizado tal qual se descreveu previamente ao caracterizar o ergômetro ${ }^{4}$. Foi utilizado um sinal acústico para ditar o ritmo de pedaladas dos atletas (60 ciclos/min.). Cada FID foi adquirido da perna direita do atleta a cada $2 \mathrm{~s}$ (duas pedaladas). A sincronização entre o pulso de excitação e o final do deslocamento do pedal foi conseguida mediante o sincronizador cardíaco, padrão do espectrômetro Signa. Foi instalado um interruptor ao final do pedal direito do
Figura 3 - Espectros de ${ }^{3 / P}$-ERM do músculo vasto medial



ergômetro de maneira que, cada vez, que o pedal chegava a este ponto e a perna ficava completamente estendida e em repouso, o interruptor produzia um sinal que, através de uma interface desenvolvida pelos técnicos da General Electric, produzia um sinal equivalente à onda $\mathrm{Q}$ do eletrocardiograma. Esse sinal atuava através do circuito de sincronização com o ritmo cardíaco disparando a aquisição. Utilizou-se um sistema eletrocardiográfico Hewllett-Packard 78352 A, acoplado ao espectrômetro Signa, para seguir e mostrar digitalmente o correto seguimento por parte do atleta da freqüência pré-estabelecida do exercício.

Durante os períodos de repouso, a periodicidade na aquisição das FID's se manteve mediante outra interface, desenvolvida também pelo grupo da General Electric, que gerava um sinal elétrico de um milivolt de maneira contínua, na freqüência pré-determinada, no caso, a cada dois segundos.
Os FIDs de fósforo foram analisados com AMARES, um algoritmo de ajuste não linear de mínimos quadrados no domínio de tempo (Vanhamme et al, 1997). A função modelo no domínio do tempo estava composta por 13 sinusóides que se atenuavam de maneira exponencial e que correspondiam aos 13 picos no domínio da freqüência atribuídos às ressonâncias de interesse, como: fosfomonoésteres (PME), fosfato inorgânico (Pi), fosfodiésteres (PDE), fosfocreatina (PCr), g-ATP (2 picos), a-ATP (2 picos), NAD, b-ATP (3 picos) (Figura 3).

\section{Análise estatística dos resultados}

Para a análise das variáveis $\mathrm{PCr}$, Pi e pH no protocolo experimental de ${ }^{3 / P}$-ERM dinâmico realizado com os fundistas, foram utilizados modelos lineares mistos. Dado que as variáveis foram observadas sob diferentes condições experimentais, consideramos o modelo de medidas repetidas ${ }^{5}$. 
Para a análise das variações de $\mathrm{PCr}$ e $\mathrm{Pi}, \mathrm{o}$ melhor modelo para o ajuste foi o de "Compound Symmetry", enquanto que para o caso do $\mathrm{pH}$, foi o da "estrutura de Toepliz" 5 . O nível mínimo aceito para estabelecer significância estatística em todos os casos foi de $p<0,05$.

\section{Resultados}

A Tabela I apresenta as características antropométricas dos atletas antes e depois do período de suplementação com creatina. No entanto, não há diferenças significativas entre os grupos, nem depois do período de suplementação.

Todos os valores de PCr, Pi e pH utilizados para a análise estatística foram obtidos como médias dos cinco espectros processados automaticamente, correspondentes às somas durante os últimos 10 segundos de cada período correspondente (repouso, exel, recl, exe2, rec2, exe3, rec3). Houve uma exceção no caso do rec3, em que o período do ponto médio foi situado no final do espectro, devido ao desaparecimento do Pi visível na parte do período $\operatorname{rec} 3^{6}$.

A modelização por separado das variações de níveis de $\mathrm{PCr}$, Pi e valores de $\mathrm{pH}$ não demonstrou diferenças significativas entre os grupos antes da suplementação. No entanto, houve diferença estatisticamente significativa depois do período de suplementação com creatina, em relação à PCr e ao Pi (modelo de Compound Symmetry), assim como o pH (estrutura de Toepliz). Entretanto, não foi encontrada diferença significativa nos períodos de recuperação (Tabela 2).

Em relação ao $\mathrm{Pi}$, a variação dos valores com respeito ao valor inicial em repouso apresenta diferença estatística significativa $(p=0,00 \mathrm{I})$ na interação grupo-estado, devido basicamente às diferenças na rec3 $(p=0,001)$ e uma tendência à significância $(p=0,064)$ no exe3. O grupo I acumula menor quantidade de $\mathrm{Pi}$, especialmente no final do protocolo de exercício (exe3, rec3) (Tabela 3).

Em relação aos valores de $\mathrm{pH}$ depois da suplementação, detectamos um efeito do grupo ao nível de tendência $(p=0,08 \mathrm{l})$, observamos valores absolutos de $\mathrm{pH}$ superiores no grupo I na maior parte do protocolo de exercício (Tabela 4).

\begin{tabular}{|c|c|c|c|c|c|}
\hline $\begin{array}{c}\text { Características } \\
\text { antropométricas }\end{array}$ & & $\begin{array}{c}\text { Grupo I } \\
\text { antes }\end{array}$ & $\begin{array}{l}(n=7) \\
\text { depois }\end{array}$ & $\begin{array}{c}\text { Grupo } 2 \\
\text { antes }\end{array}$ & $\begin{array}{l}(n=7) \\
\text { depois }\end{array}$ \\
\hline Idade & $x$ & 26,1 & 26,1 & 27,1 & 27,1 \\
\hline (anos) & SD & 5,08 & 5,08 & 3,16 & 3,16 \\
\hline Peso & $x$ & 60,6 & 60,2 & 59,6 & 59,6 \\
\hline$(\mathrm{kg})$ & $S D$ & 7,57 & 6,4 & 5,24 & 5,2 \\
\hline Altura & $x$ & 1,75 & 1,75 & 1,72 & 1,72 \\
\hline$(\mathrm{m})$ & $S D$ & 0,07 & 0,07 & 0,04 & 0,04 \\
\hline IMC & $x$ & 19,7 & 21,78 & 20,2 & 20,51 \\
\hline$\left(\mathrm{kg} / \mathrm{m}^{2}\right)$ & SD & 1,32 & 2,37 & 1,80 & 2,92 \\
\hline
\end{tabular}

Tabela 2 - Valores médios de $\mathrm{PCr}$ (unidades arbitrárias) durante o repouso e o protocolo de exerć́cio de ERM realizado no CDP

\begin{tabular}{|c|c|c|c|c|c|c|c|c|c|}
\hline $\mathrm{PCr}$ & & $\begin{array}{c}\text { Grupo I } \\
\text { antes }\end{array}$ & $\begin{array}{l}\% \mathrm{PCr} \\
\text { rem. }^{\#}\end{array}$ & $\begin{array}{l}(n=5) \\
\text { depois }\end{array}$ & $\begin{array}{l}\% \mathrm{PCr} \\
\text { rem. }{ }^{\#}\end{array}$ & $\begin{array}{c}\text { Grupo } 2 \\
\text { antes }\end{array}$ & $\begin{array}{l}\% \mathrm{PCr} \\
\text { rem. }{ }^{\#}\end{array}$ & $\begin{array}{l}(n=7) \\
\text { depois }\end{array}$ & $\begin{array}{l}\% \mathrm{PC} r \\
\text { rem. }{ }^{\#}\end{array}$ \\
\hline $\begin{array}{c}\text { Repouso } \\
\text { SD }\end{array}$ & $x$ & $\begin{array}{l}0,81 \\
0,01\end{array}$ & 100 & $\begin{array}{l}0,86 \\
0,01\end{array}$ & 100 & $\begin{array}{l}0,73 \\
0,02\end{array}$ & 100 & $\begin{array}{l}0,74 \\
0,01\end{array}$ & 100 \\
\hline $\begin{array}{c}\text { Exe I } \\
\text { SD }\end{array}$ & $x$ & $\begin{array}{l}0,34 \\
0,01\end{array}$ & 42 & $\begin{array}{l}0,44 * \\
0,02\end{array}$ & 54 & $\begin{array}{l}0,25 \\
0,06\end{array}$ & 34 & $\begin{array}{l}0,22 \\
0,01\end{array}$ & 30 \\
\hline $\begin{array}{l}\operatorname{Rec} \mid \\
S D\end{array}$ & $x$ & $\begin{array}{l}0,75 \\
0,03\end{array}$ & 93 & $\begin{array}{l}0,71 \\
0,18\end{array}$ & 83 & $\begin{array}{l}0,65 \\
0,03\end{array}$ & 89 & $\begin{array}{l}0,63 \\
0,03\end{array}$ & 85 \\
\hline $\begin{array}{l}\text { Exe } 2 \\
\text { SD }\end{array}$ & $x$ & $\begin{array}{l}0,35 \\
0,01\end{array}$ & 43 & $\begin{array}{c}0,45 * \\
0,02\end{array}$ & 52 & $\begin{array}{l}0,30 \\
0,01\end{array}$ & 41 & $\begin{array}{l}0,27 \\
0,01\end{array}$ & 36 \\
\hline $\begin{array}{l}\operatorname{Rec} 2 \\
S D\end{array}$ & $x$ & $\begin{array}{l}0,73 \\
0,15\end{array}$ & 90 & $\begin{array}{l}0,74 \\
0,07\end{array}$ & 86 & $\begin{array}{l}0,70 \\
0,03\end{array}$ & 96 & $\begin{array}{l}0,63 \\
0,03\end{array}$ & 85 \\
\hline $\begin{array}{l}\text { Exe } 3 \\
\text { SD }\end{array}$ & $x$ & $\begin{array}{l}0,35 \\
0,01\end{array}$ & 43 & $\begin{array}{l}0,47 * \\
0,02\end{array}$ & 55 & $\begin{array}{l}0,31 \\
0,01\end{array}$ & 42 & $\begin{array}{l}0,29 \\
0,01\end{array}$ & 39 \\
\hline $\begin{array}{l}\operatorname{Rec} 3 \\
S D\end{array}$ & $x$ & $\begin{array}{l}0,83 \\
0,02\end{array}$ & 102 & $\begin{array}{l}0,85 \\
0,02\end{array}$ & 99 & $\begin{array}{l}0,76 \\
0,01\end{array}$ & 104 & $\begin{array}{l}0,74 \\
0,02\end{array}$ & 100 \\
\hline
\end{tabular}

\# : Porcentagem de $\mathrm{PCr}$ remanescente com respeito ao valor inicial em repouso *: diferença estatisticamente significativa entre grupo I e grupo 2 pós-suplementação. $n=5$ no grupo $\mid$ por problemas no processamento automatizado em um dos atletas, enquanto que 0 outro não realizou 0 protocolo por lesão.

\begin{tabular}{|c|c|c|c|c|c|}
\hline \multicolumn{6}{|c|}{$\begin{array}{l}\text { Tabela } 3 \text { - Valores médios de Pi (unidades arbitrárias) durante o } \\
\text { repouso e o protocolo de exerć́cio de MRS realizado no CDP }\end{array}$} \\
\hline $\mathrm{Pi}$ & & $\begin{array}{c}\text { Grupo I } \\
\text { antes }\end{array}$ & $\begin{array}{l}(n=5) \\
\text { depois }\end{array}$ & $\begin{array}{c}\text { Grupo } 2 \\
\text { antes }\end{array}$ & $\begin{array}{c}(n=7) \\
\text { depois }\end{array}$ \\
\hline $\begin{array}{c}\text { Repouso } \\
\text { SD } \\
\text { Exe I } \\
\text { SD } \\
\text { Rec I } \\
\text { SD } \\
\text { Exe } 2 \\
\text { SD } \\
\operatorname{Rec} 2 \\
\text { SD } \\
\text { Exe } 3 \\
\text { SD } \\
\operatorname{Rec} 3 \\
\text { SD }\end{array}$ & $\begin{array}{l}x \\
x \\
x \\
x \\
x \\
x\end{array}$ & $\begin{array}{l}0,10 \\
0,06 \\
0,39 \\
0,01 \\
0,15 \\
0,09 \\
0,40 \\
0,01 \\
0,12 \\
0,05 \\
0,39 \\
0,01 \\
0,04 \\
0,04\end{array}$ & $\begin{array}{l}0,11 \\
0,01 \\
0,52 \\
0,03 \\
0,25 \\
0,19 \\
0,44 \\
0,02 \\
0,26 \\
0,15 \\
0,38 \\
0,02 \\
0,07 * \\
0,08\end{array}$ & $\begin{array}{l}0,08 \\
0,01 \\
0,48 \\
0,09 \\
0,16 \\
0,26 \\
0,34 \\
0,02 \\
0,09 \\
0,05 \\
0,43 \\
0,01 \\
0,15 \\
0,13\end{array}$ & $\begin{array}{l}0,10 \\
0,02 \\
0,55 \\
0,02 \\
0,15 \\
0,08 \\
0,49 \\
0,02 \\
0,13 \\
0,02 \\
0,47 \\
0,01 \\
0,31 \\
0,20\end{array}$ \\
\hline
\end{tabular}

*: Diferença estatisticamente significativa entre grupo | e grupo 2 pós-suplementação. 


\section{Tabela 4 - Valores médios de $\mathrm{pH}$ durante o repouso e o protocolo de exercício de MRS realizado no CDP}

\begin{tabular}{|c|c|c|c|c|c|}
\hline PH & & $\begin{array}{c}\text { Grupo I } \\
\text { antes }\end{array}$ & $\begin{array}{l}(n=5) \\
\text { depois }\end{array}$ & $\begin{array}{c}\text { Grupo } 2 \\
\text { antes }\end{array}$ & $\begin{array}{l}(n=7) \\
\text { depois }\end{array}$ \\
\hline Repouso & $x$ & 7,05 & 7,06 & 7,06 & 7,04 \\
\hline SD & & 0,05 & 0,03 & 0,03 & 0,03 \\
\hline Exe I & $x$ & 6,97 & 6,94 & 6,96 & 6,93 \\
\hline$S D$ & & 0,04 & 0,07 & 0,07 & 0,06 \\
\hline $\operatorname{Rec} \mid$ & $x$ & 6,95 & $6,93 *$ & 6,93 & 6,81 \\
\hline SD & & 0,05 & 0,04 & 0,10 & 0,12 \\
\hline Exe 2 & $x$ & 7,01 & 7,00 & 6,99 & 6,99 \\
\hline SD & & 0,05 & 0,09 & 0,12 & 0,08 \\
\hline $\operatorname{Rec} 2$ & $x$ & 6,94 & 6,89 & 7,01 & 6,85 \\
\hline SD & & 0,14 & 0,14 & 0,32 & 0,09 \\
\hline Exe 3 & $x$ & 7,00 & 6,98 & 7,01 & 7,02 \\
\hline SD & & 0,04 & 0,05 & 0,07 & 0,03 \\
\hline $\operatorname{Rec} 3$ & $x$ & 7,02 & 6,96 & 6,83 & 6,86 \\
\hline SD & & 0,18 & 0,09 & 0,19 & 0,11 \\
\hline
\end{tabular}

*: Diferença estatisticamente significativa entre grupo I e grupo 2 pós-suplementação.

\section{Discussão}

Os resultados obtidos com o consumo de $\mathrm{PCr}$ durante o protocolo de exercício apresentaram diferenças estatisticamente significativas, depois do período de suplementação com creatina, na redução do consumo de $\mathrm{PCr}$ durante os três períodos do exercício. Por outro lado, a falta de significância da diferença entre os grupos nos níveis de $\mathrm{PCr}$, nos períodos de recuperação, sugere que o processo de ressíntese de $\mathrm{PCr}$ nos períodos mencionados, considerado um índice da capacidade oxidativa dos atletas estudados ${ }^{7,8,9}$, não é um fator limitante em nenhum dos casos (placebo ou creatina). Já que, como foi comentado, a potência desenvolvida pós-suplementação não foi distinta para os dois grupos, pois o menor consumo de PCr pela via anaeróbica aláctica não foi devido a uma diminuição da demanda pela realização de menor potência, e sim por um aumento da produção de energia por outras vias. Cabe considerar, portanto, como possíveis causas deste menor consumo de $\mathrm{PCr}$ uma utilização da via glucolítica anaeróbica e a fosforilação oxidativa mitocondrial. Os dados obtidos no protocolo de exercício no CDP para a variação de $\mathrm{pH}$ não apresentaram uma maior acidificação no caso do grupo I, o que sugeriria uma maior ativação da via glucolítica. Ao contrário, o pH intracelular no músculo dos atletas do grupo I pós-suplementação se acidifica menos que no do grupo 2. Entretanto, a hidrólise da $\mathrm{PCr}$ basifica o pH intracelularr ${ }^{10}$ e a menor hidrólise de $\mathrm{PCr}$ nos períodos de exercício por parte do grupo I reduziria sua capacidade de um possível aumento do fluxo glucolítico. Entretanto, nos resultados do protocolo de exercício realizado na esteira rolante do CAR foi observado uma tendência a um maior acúmulo de lactato no sangue (ativação glucolítica) dos atletas do grupo 2 .

Portanto, concluímos que a via metabólica que aparece ativada devido à suplementação com creatina no caso do grupo I é a fosforilação oxidativa. Nossos resultados estariam de acordo com alguns trabalhos anteriores, realizados com biópsias. Assim, já observaram em indivíduos ativos" uma diminuição do consumo de $\mathrm{PCr}$ devido à suplementação com 20g/dia ${ }^{-1}$ de creatina durante seis dias. Concretamente, o consumo de $\mathrm{PCr}$ depois de cinco períodos de seis segundos de exercício de alta intensidade, intercalados com 30 segundos de recuperação passiva entre os períodos, foi menor depois da suplementação (2l\%) que antes da suplementação (43\%). Assim, o acúmulo de lactato muscular foi menor depois do período de suplementação $(25,2 \mathrm{mmol}$ ( $\mathrm{kg}$ peso seco-1) que antes da suplementação $\left(44,3 \mathrm{mmol}(\mathrm{kg} \text { peso seco })^{-1}\right)$. Entretanto, a concentração de creatina não fosforilada foi a que aumentou significativamente (29\% maior depois da suplementação).
Neste estudo pudemos demonstrar que, mesmo depois de um período de exercício intenso de 2 minutos e I minuto de recuperação passiva, ocorre a recuperação no nível de repouso da PCr. Sendo que a velocidade de resíntese de $\mathrm{PCr}$ é realmente mais rápida depois da suplementação com $\mathrm{Cr}$, esses resultados estão de acordo com estudos realizados com biópsias ${ }^{11,12}$. Entretanto, nosso protocolo de estudo permitiu avaliar, de maneira contínua e sem necessidade de biópsia, as concentrações de PCr, tanto durante o exercício como na recuperação, verificando que não apenas produz um aumento na velocidade de ressíntese de $\mathrm{PCr}$ durante a fase de recuperação, mas também durante a fase de exercício desde a primeira série de 2 minutos. Cabe assinalar que, quando o protocolo de exercício $^{12}$ é realizado em condições de isquemia, mediante aplicação de um torniquete antes do início do protocolo, não se detecta diferença entre a concentração de $\mathrm{PCr}$ no início do período de recuperação, tanto antes como depois da suplementação com creatina. Esse fato está de acordo porque quando o consumo de oxigênio por parte do músculo está restrito, a suplementação com creatina não pode exercer efeito sobre a redução do consumo de $\mathrm{PCr}$ durante o exercício, apontando, como em nosso caso, uma ativação do metabolismo oxidativo devido à suplementação com creatina. Neste sentido, a contribuição do metabolismo aeróbico em exercícios intermitentes de alta intensidade (sprints de 30 segundos, separados por quatro minutos de recuperação) pode ser elevado (cerca de 49\% da energia consumida no segundo sprint do protocolo ${ }^{13}$ teria origem aeróbica). Estudos recentes "in vitro" com mitocôndrias isoladas demonstraram de forma conclusiva a ativação da respiração mitocondrial mediante a adição de concentrações fisiológicas de creatina ${ }^{14}$. Nossos dados concordam, portanto, com a hipótese de que a suplementação com creatina atuaria como um modulador positivo do metabolismo aeróbico muscular, incluso durante os períodos de exercício.

\section{Conclusão}

O protocolo de exercício realizado pelos fundistas no CDP detectou, mediante ${ }^{3 /} \mathrm{P}$ ERM, uma diminuição do consumo de $\mathrm{PCr}$ durante os períodos de exercício devido à 
suplementação com creatina. Como o pH intracelular não diminuiu no grupo creatina, pelo contrário, aumentou ou se manteve igual em relação ao grupo placebo, concluímos que o aporte energético necessário para desenvolver a mesma potência no grupo suplementado com creatina deve provir de um aumento da contribuição da fosforilação oxidativa com respeito ao grupo controle. Dado que não foi detectado um aumento significativo do cociente PCr/ATP durante o período da suplementação em nenhum dos dois grupos, cabe considerar que o efeito detectado se deve a variações na concentração de $\mathrm{Cr}$ livre não-fosforilada.

\section{Conflito de interesse: não há.}

\section{SUMMARY}

\section{Muscular energetic metabolism STUDY IN ATHLETES BY ${ }^{31}$ P-MRS}

BACKGROUND. The aim of this study was to characterize the muscular reservoirs of phosphorilated energetic components of athletes using ${ }^{3 /} P-M R S$.

METHODS. The sample wasformed by $/ 4$ elite athletes from the Center for High Sportive Performance(CAR, Sant CugatdelVallés, Spain). The pattern of the phosphorilated metabolites was measured from the muscle vastus medialis by ${ }^{3 /}$ P-MRS. Oral supplementation of $20 \mathrm{~g}$ of Creatine monohydrate was given during $/ 4$ days. Two groups ofathletes were formedaccording to their physical characteristics (weight, height, body mass index, maximum $O 2$ uptake). The first group received a placebo (maltodextrine), while the second group received a diet of creatine supplement. The exercise was performed inside the resonance tunne/ with a frequency of 60RPM with both legs.

RESULTS. The results showed that significant decrease occurred in phosphocreatine (PCr), inorganic phosphate (Pi) and intracellular $\mathrm{pH}$ after supplementation.

CONCLUSION. It was concluded that the exercise performed by the long distance runners recruited in this study, detected by ${ }^{31} P-M R S$, reduced the consumption of $P C$ Crduring exercise owing to creatine supplementation diet. [Rev Assoc Med Bras 2004; 50(2): 127-32]

KEY WORDS: Creatine supplementation. Magnetic resonance spectroscopy.

\section{REFERÊNCIAS}

I. Balsom PD, Soderlund K, Ekblom B. Creatine in humans with special reference to creatine supplementation. Sports Med 1994; 1 8:268-84.

2. Grazi E, Magri E, Balboni G. On the control of arginine metabolism in chicken, kidney and liver. Eur J Biochem 1975; 60:43 I-6.

3. Williams MH, Kreider RB, Branch JD. Creatina. São Paulo: Manole; 2000.

4. González de Suso JM, Bernús G, Alonso J, Alay A, Capdevila A, Gili J, et al. Development and characterization of an ergometer to study the bioenergetics of the human quadriceps muscle by ${ }^{31}$ P-NMR spectroscopy inside a standard MR scanner. Magn Resonance Med 1993; 29:575-81.

5. Littell RC, Henry PR, Ammerman CB. Statistical analysis of repeated measures data using SAS procedures. J Anim Sci 1998; 76: |2 |6-3|

6. Bendahan D, Confort-Gouny S, Kozak-
Ribbens G, Cozzone PJ. Pi trapping in glycogenolytic pathway can explain transient $\mathrm{Pi}$ disappearance during recovery from muscular exercise. FEBS Lett 1990; 269:402-5.

7. Taylor DJ, Bore PJ, Styles P, Gadian DG, Radda GK. Bioenergetics of intact human muscle. A ${ }^{3} \mathrm{P}$ nuclear magnetic resonance study. Mol Biol Med 1983; I:77-94.

8. Radda GK. The use of NMR spectroscopy for the understanding of disease. Science 1986; 223:640-5.

9. Achten E, Van Cauteren M, Willem R. ${ }^{31} \mathrm{P}$ NMR spectroscopy and the metabolic properties of different muscle fibers. J Appl Physiol 1990; 68:644-9.

10. Tanokura M, Yamada K. Changes in intracellular $\mathrm{pH}$ and inorganic phosphate concentration during and after muscle contraction as studied by time-resolved ${ }^{31} \mathrm{P}$ NMR. FEBS Letters 1984; 171: |65-8.

I I. Balsom PD, Soderlund K, Sjodin B, Ekblom B. Skeletal muscle metabolism during short duration high-intensity exercise: influence of creatine supplementation. Acta Physiol Scand 1995; I 55:303- 10.

12. Greenhaff PL, Bodin K, Soderlund K, Hultman E. Effect of oral creatine supplementation on skeletal muscle phosphocreatine resynthesis. Am J Physiol 1994; 266:E725-E30.

13. Bogdanis GC, Nevill ME, Boobis LH, Lakomy HKA. Contribution of phosphocreatine and aerobic metabolism energy supply during repeated sprint exercise. J Appl Physiol. 1996; 80:876-84.

14. Kay L, Nicolay K, Wieringa B, Salks V, Wallimann $T$. Direct evidence for the control of mitochondrial respiration by mitochondrial creatine kinase in oxidative muscle cells in situ. J Biol Chem 2000; 272:6937-44.

Artigo recebido: 10/07/02 Aceito para publicação: 04/03/04 